\title{
Методические аспекты архитектурного проектирования комплексов науки и инноваций
}

\author{
И.В.Дианова-Клокова, ОНИР ГИПРОНИИ РАН, Москва \\ Д.А.Метаньев, ОНИР ГИПРОНИИ РАН, Москва
}

Архитектурное проектирование объектов, предназначенных для научно-инновационной деятельности, имеет ряд особенностей, определяемых самой этой деятельностью; её отличают взаимопроникновение отраслей, междисциплинарность методов, усложнение объектов и инструментов исследований. Принципиальная коллизия между опережающими темпами развития науки и отставанием темпов проектирования и строительства для неё ставит специалистов перед необходимостью решения сложных задач, обусловленных природой научного производства. Разрешение данной коллизии связано с разработкой принципиальных методов проектирования, способных соответствовать часто меняющимся технологиями исследований, трансформации и усложнению структуры научных комплексов. В статье рассмотрена эволюция методов проектирования, таких как унификация решений, нормирование, универсализация пространства, типизация проектов применительно к проектированию объектов научно-инновационного назначения. Нормативная база проектирования научных объектов сформирована в проектном и научно-исследовательском институте Академии наук; она широко использовалась всеми ведомствами на территории нашей страны. Приведены материалы по специальным методам - модульному регулированию на всех уровнях проектных решений, созданию объектов и предъявлению их пользователю в различной степени завершенности; эти методы предопределяют цельность объектов и возможности для совершенствования и развития. Приведённые материалы свидетельствуют о том, что применяемые методы проектирования позволили решить сложнейшие задачи создания разнообразных научных объектов. Работы в этой области соответствовали мировому уровню требований и стандартов. Многие из построенных объектов успешно функционируют по сей день, представляя собой примеры достижений отечественной архитектуры. Показано, как с использованием приведённых методов в стране была создана практически заново мощная материально-пространственная база фундаментальной науки и инноваций.

Ключевые слова: фундаментальная наука и инновации, методики архитектурного проектирования, материально-пространственная база Академии наук.

Methodological Aspects of the Architectural Design of Science and Innovation Complexes

\section{I.V.Dianova-Klokova, ONIR GIPRONII RAN, Moscow}

\section{D.A.Metanyev, ONIR GIPRONII RAN, Moscow}

The architectural design of objects intended for scientific and innovative activity has a number of features determined by this activity, which is distinguished by the interpenetration of industries, the interdisciplinary of methods, the complexity of objects and research tools. The fundamental conflict between the outstripping pace of development of science and the lagging pace of design and construction for it poses for specialists the need to solve complex problems due to the nature of scientific production. The resolution of this conflict is associated with the development of fundamental design methods that can satisfy the frequently changing technologies of research, transformation and the complexity of the structure of scientific complexes. The article considers the evolution of design methods, such as unification of solutions, rationing, universality of space, typing of projects, as applied to the design of objects of scientific and innovative purpose. The regulatory framework for the design of scientific objects, widely used by all departments in Russia, is formed at the design and research institute of the Academy of Sciences. Materials are presented on special methods modular regulation at all levels of design decisions, design and construction according to the levels of specialization; these methods predetermine the integrity of objects and the possibilities of their improvement and development. The cited materials indicate that the applied design methods have made it possible to solve the most complex problems of creating a variety of scientific objects. Work in this area corresponded to the world level of requirements and standards. Many of the constructed facilities have been successfully operating to this day, presenting examples of achievements of domestic architecture. It is shown how, using the above methods, a powerful material and spatial base of fundamental science and innovations was practically created anew in the country.

Keywords: fundamental science and innovation, architectural design methods, material and spatial base of the Academy of Sciences.

Архитектурное проектирование объектов, предназначенных для научно-инновационной деятельности, имеет ряд особенностей, определяемых самой этой деятельностью; её всегда отличали взаимопроникновение отраслей, междисциплинарность методов, усложнение объектов и инструментов исследований. На это в своё время обращали внимание и В.И. Вернадский, и А. Эйнштейн [1, с. 150; 2, с. 111]. Эти отличия ставили свои задачи перед архитекторами, создающими пространства для науки и инноваций, а также требовали соответствующих всё новых методических подходов к проектированию. Для изучения их эволюции наиболее интересно и 
целесообразно обратиться к опыту второй половины XX века, периоду расцвета отечественной науки, когда развитие науки отличалось ростом её финансирования и численности научных сотрудников, увеличением объёмов и ускорением строительства научных зданий и комплексов, совершенствованием материально-пространственной базы [3]. Методы проектирования в то время развивались особенно быстро.

Важнейшей и принципиальной проблемой стала коллизия между опережающими темпами развития науки и отставанием темпов проектирования и строительства для неё, ведущая к тому, что исходные положения, заложенные в первоначальный проект, зачастую оказывались нежизнеспособными и подвергались неоднократным изменениям. Особенно острой коллизия была в области фундаментальных наук и инноваций. Вставала необходимость решения целого ряда задач, обусловленных часто меняющимися технологиями, трансформацией и усложнением структуры научно-инновационных комплексов. Это требовало соответствующих проектных решений и новых приёмов проектирования.

Эволюцию развития новых подходов к проектированию мы проследим на примере деятельности проектного института Академии наук (позже ГИПРОНИИ), где концентрировались архитектурно-строительные проблемы поиска оптимальных пространств, способных вместить научно-инновационные процессы (в том числе и их будущее развитие), задачи инженерно-технического и технологического обеспечения этих процессов. При этом необходимо было улучшать условия труда учёных и сокращать удельные затраты. Деятельность Института осуществлялась под эгидой выдающихся учёных мирового уровня, таких как А.П.
Александров, Л.А. Арцимович, Н.Г. Басов, Е.П. Велихов, А.П. Виноградов, П.Л. Капица, В.А. Котельников, М.А. Лаврентьев, А.Н. Несмеянов, Ю.А. Овчинников, А.М. Прохоров, Н.Н. Семёнов, Г.К. Скрябин, В.А. Трапезников, Г.М. Франк, С.А. Христианович [4]... На протяжении ряда лет создавалась определённая система проектирования, предопределяющая цельность и завершённость и имеющая потенциальные резервы для совершенствования и развития. Изначально важнейшими инструментами этой системы стали унификация решений, нормирование, универсализация пространства, типизация проектов.

В течение послевоенных десятилетий базой проектирования явилась унификация объёмно-планировочных и градостроительных решений. При этом рамки её последовательно расширялись, совершенствовалась функциональная и компоновочная организация научных комплексов.
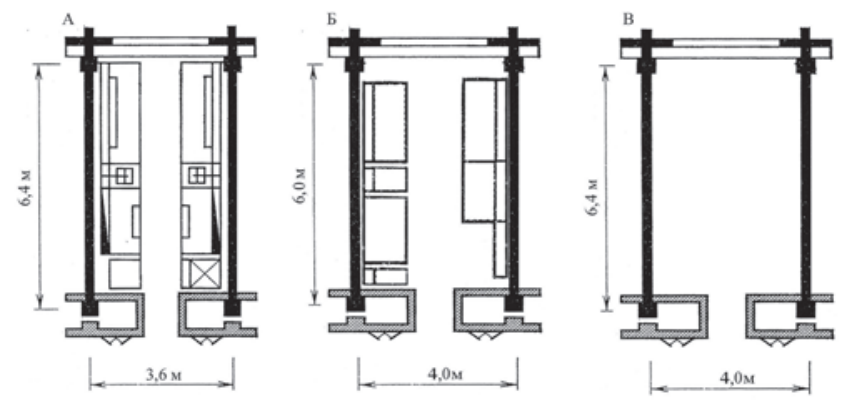

Pис. 1. Унифицированные лабораторные ячейки с коммуникационными нишами. Специализированные: $A$ - для химических и биологических наук, $Б$ - для физических наук. $B$ - универсальная для химических, биологических и физических наук
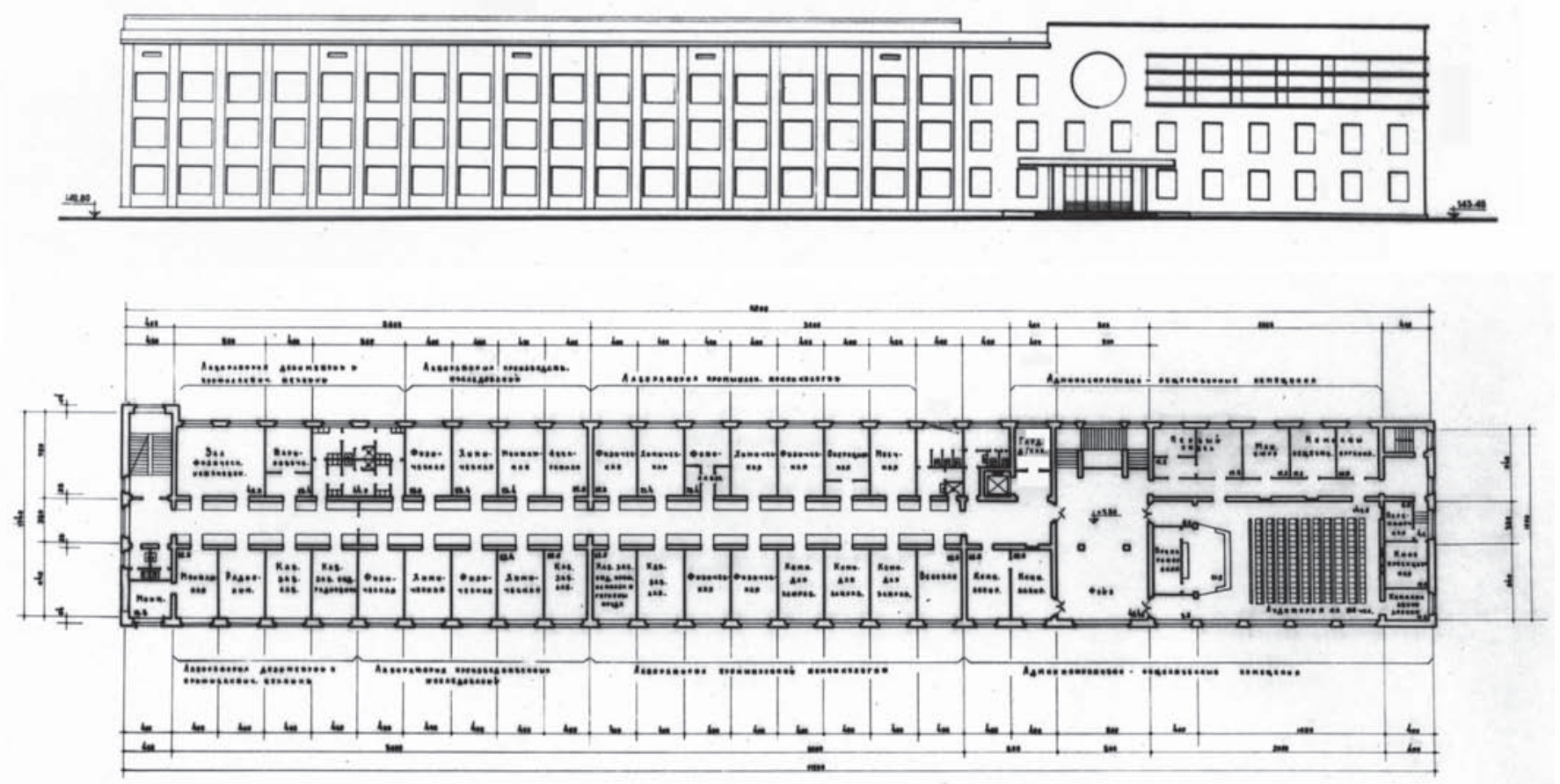

Pис. 2. Лабораторный корпус Института экспериментальной биологии и медицины Новосибирского Академгородка СО АН СССР. Проект применён для строительства шести институтов Академгородка 
В 1946-1955 годы проектировались отдельные здания научно-исследовательских институтов, в которых определялись и фиксировались помещения нужного объёма и площади для размещения того или иного лабораторного процесса. Были установлены значения параметров первых унифицированных лабораторных помещений для физического и химического профилей исследования. Они применены в проектировании и строительстве институтов так называемого «IV участка» $\mathrm{AH}$ СССР на Ленинском проспекте в Москве: Института органической химии, Физического института, Института металлургии и других.

Важным этапом стало создание в 1955-1960 годы лабораторных помещений универсального характера (размерами 4,0×6,4 м) для широкого диапазона исследований физического, химического, биологического профилей (рис. 1). Это послужило основой типизации проектных решений лабораторных зданий в пределах одной площадки строительства.

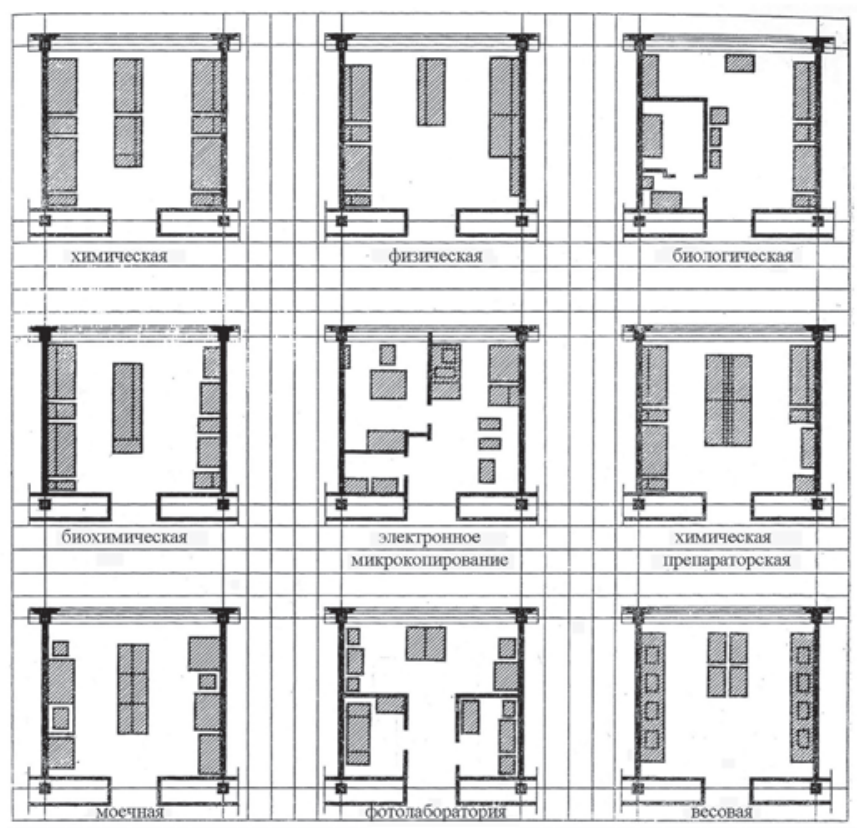

Рис. 3. Унифицированные лабораторные помещения на основе сетки $6 \times 6 \mathrm{~m}$

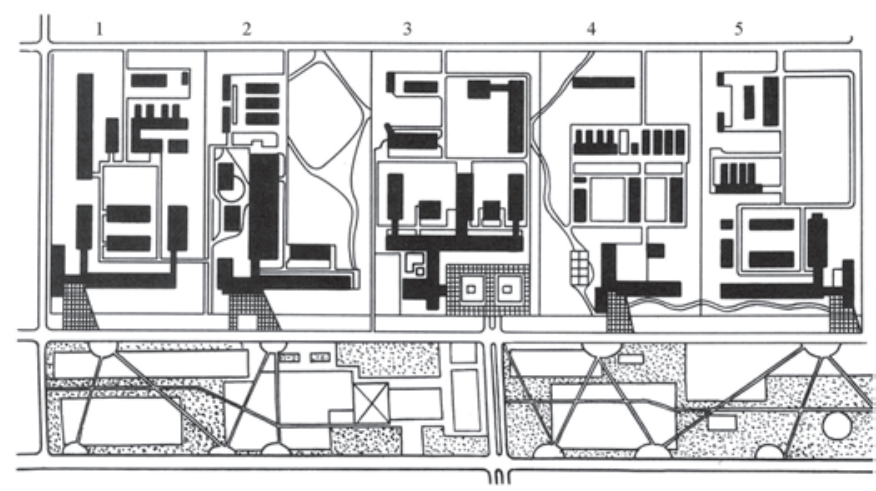

Рис. 4. Планировка научной зоны Научного центра биологических исследований в городе Пущино: 1 - Институт физиологии и биохимии микроорганизмов; 2 - КБ биологического приборостроения; 3 - Институт белка; 4 - Институт биофизики; 5 - Институт фотосинтеза
Так были запроектированы и построены филиал Института радиотехники и электроники во Фрязино Московской области, шесть лабораторных корпусов Новосибирского научного центра Сибирского отделения АН СССР (рис. 2) [5] и др.

В 1960-1965 годы под давлением строительного комплекса и в связи со значительным увеличением объёма строительных работ во всех областях народного хозяйства возникла необходимость внедрения общесоюзных стандартов, обеспечивающих максимальную индустриализацию строительства. Этот процесс коснулся и объектов научного назначения. На основе конструктивной сетки $6 \times 6$ м были разработаны наборы унифицированных лабораторных помещений, созданы типовые проекты лабораторных зданий (рис. 3).

Применение типовых решений позволило резко сократить сроки проектирования и строительства научных учреждений и построить лабораторные здания для институтов Москвы, подмосковных научных центров и многих городов страны.

Процессы совершенствования методик проектирования, начавшись с выработки типовых ячеек, были продолжены типовыми секциями и блоками. В 1965-1970 годы были разработаны серии унифицированных планировочных секций с полным набором коммуникационных и технических блоков для зданий лабораторий. Они обеспечивали возможность более широкой вариантности решений, удовлетворяющих целому ряду градостроительных, функциональных, организационных требований. Кроме того, достигалась возможность трансформации рабочих площадей. Всё это способствовало универсализации пространства для научных исследований.

Предполагалось, что основная часть подразделений научного комплекса могла формироваться на основе создания объектов многоцелевого назначения со стандартными конструктивными элементами. Для зданий, имеющих важное композиционное значение, а также для лабораторий с особым технологическим режимом использовались индивидуальные решения с применением отдельных типовых элементов.

Однако масштабы строительства новых научных центров настоятельно выдвигали задачу внедрения приёмов унификации не только применительно к отдельным сооружениям, но и в градостроительном плане.

Впервые предложение о применении этих приёмов к планировочной организации территории строительства целой группы научно-исследовательских институтов было реализовано в подмосковном Научном центре биологических исследований АН СССР в Пущино. Научная зона расчленялась на модульные участки, рассчитанные на отдельные институты. Проектирование велось с применением типовых лабораторных корпусов. Участки имели глубинное функциональное зонирование по схеме: блоки административно-общественного назначения, общие лаборатории, специальные установочные лаборатории, экспериментальные мастерские и производства, склады. Предложенное в проекте «Пущино» зонирование стало своеобразным регламентом застройки институтских территорий (рис. 4) [8; 12]. Этот приём получил распространение 
при проектировании и других подмосковных академических научных городков. В проекте Научно-исследовательского центра физических исследований АН СССР в Троицке в 1965 году была предложена система расчленения всей территории на планировочный модуль $60 \times 60$ м, которому должно было подчиниться проектирование всех сооружений комплекса. На этой основе здесь были построены некоторые лаборатории и экспериментальные корпуса павильонного типа. В Научном центре химических исследований в Черноголовке ряд институтов также построен из унифицированных блоков (рис. 5).

В 1967 году по распоряжению президиума Академии наук СССР и Комитета по науке при СМ СССР в ГИПРОНИИ было создано Отделение научно-исследовательских работ (ОНИР), и Институт приобрёл статус проектного и научноисследовательского. В Отделении велись теоретические и экспериментальные исследования по проблемам перспективного проектирования научно-исследовательских центров, НИИ и лабораторий. Работы всегда шли с учётом передового мирового и отечественного опыта развития науки и в тесном содружестве с проектными мастерскими Института. ГИПРОНИИ как головной институт сформировал нормативную базу проектирования научных объектов для страны. Были разработаны Указания по проектированию научно-исследовательских институтов и лабораторий (CH-НИИ-68) ${ }^{1}$. В дальнейшем на их основе была создана Инструкция по проектированию НИИ (CH-495-77)2 , где регламентировались архитектурные параметры, такие как: нормы площади лабораторий разных профилей исследований, площади помещений культурнобытового и общественно-научного назначения, инженерно-коммуникационных и вспомогательных подразделений. Регламентировались решения по водоснабжению и канализации, теплоснабжению, отоплению и вентиляции, газо- и электроснабжению. Регламентация генеральных планов вошла составной частью в СНиП по планировке и застройке городов, посёлков и сельских населённых пунктов ${ }^{3}$. В течение ряда лет Инструкция была обязательна к использованию всеми ведомствами при проектировании и строительстве на территории нашей страны.

Важным этапом стала разработка модульного регулирования на всех уровнях проектных решений. Установленная на основе антропометрических и эргонометрических данных первичная пространственная единица - рабочий пост, функциональный и планировочный модуль всех уровней системы - определяла параметры всех уровней, вплоть до градостроительного. Рабочий пост 1,8×1,8 м включал в себя пространство для размещения экспериментатора и рабочего

${ }^{1}$ Указания по проектированию научно-исследовательских институтов и лабораторий. СН-НИИ-68. - М., 1968.

${ }^{2}$ Инструкция по проектированию зданий научно-исследовательских учреждений СН 495-77 / Госстрой СССР. - М. : Стройиздат, 1978.

${ }^{3}$ СНиП II-60-75. Планировка и застройка городов, поселков и сельских населённых пунктов / Госстрой СССР. - М., 1976; СНиП II-89-80. Генеральные планы промышленных предприятий / Госстрой СССР. - М., 1982. стола - прибора и окружающего его пространства коммуникаций (рис. 6) [6]. Из технологически специализированных постов набирались более крупные многофункциональные единицы - рабочие места, из них - рабочие ячейки, различные по составу, габаритам и конфигурации. Планировочные границы каждого элемента системы определялись положением коммуникаций и их инженерно-техническими параметрами.
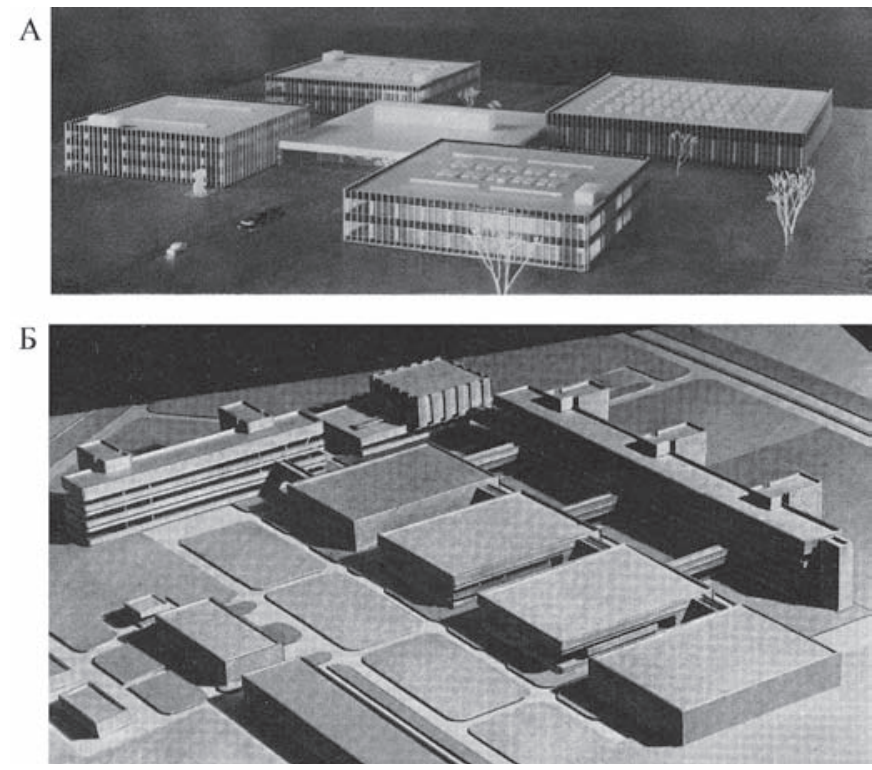

Puс. 5. А - комплекс Особого конструкторского бюро ФИАН. Научно-исследовательский центр в городе Троицке. Фото смакета; Б-комплекс Экспериментального завода научного приборостроения. Ногинский научный центр в Черноголовке. Фото с макета
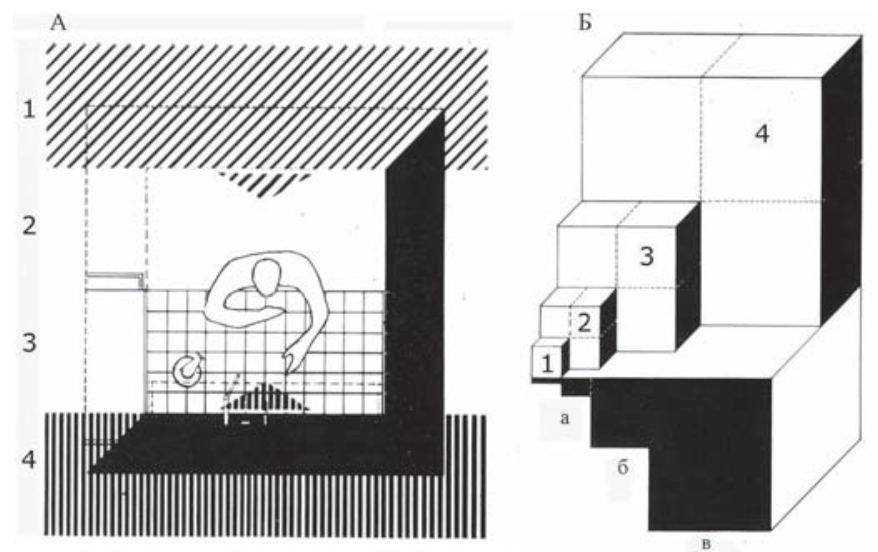

Рис. 6. Модульное регулирование на различных уровнях проектных решений. А - структура рабочего поста - первичного модуля организации пространства для научных исследований: 1 - общие коммуникации; 2 - экспериментатор; 3 - рабочий стол (прибор); 4- инженерно-технологические коммуникации. 5 - схема построения многоуровневой системы организации пространства для научных исследований. Зона деятельности: 1- рабочий пост, 2 - рабочее место, 3 - рабочая ячейка, 4 - рабочее поле. Зона коммуникаций: a- питающие линии, б - распределительные линии, в - магистральные линии 
Иерархический модульный ряд строился на основе рационального взаиморасположения зоны деятельности и зоны коммуникаций и определял всю структуру пространства. Типология взаимозаменяемых рабочих постов определялась набором оборудования для различных направлений науки (рис. 7). На этих принципах была основана методическая система, получившая название «модульного регулирования»
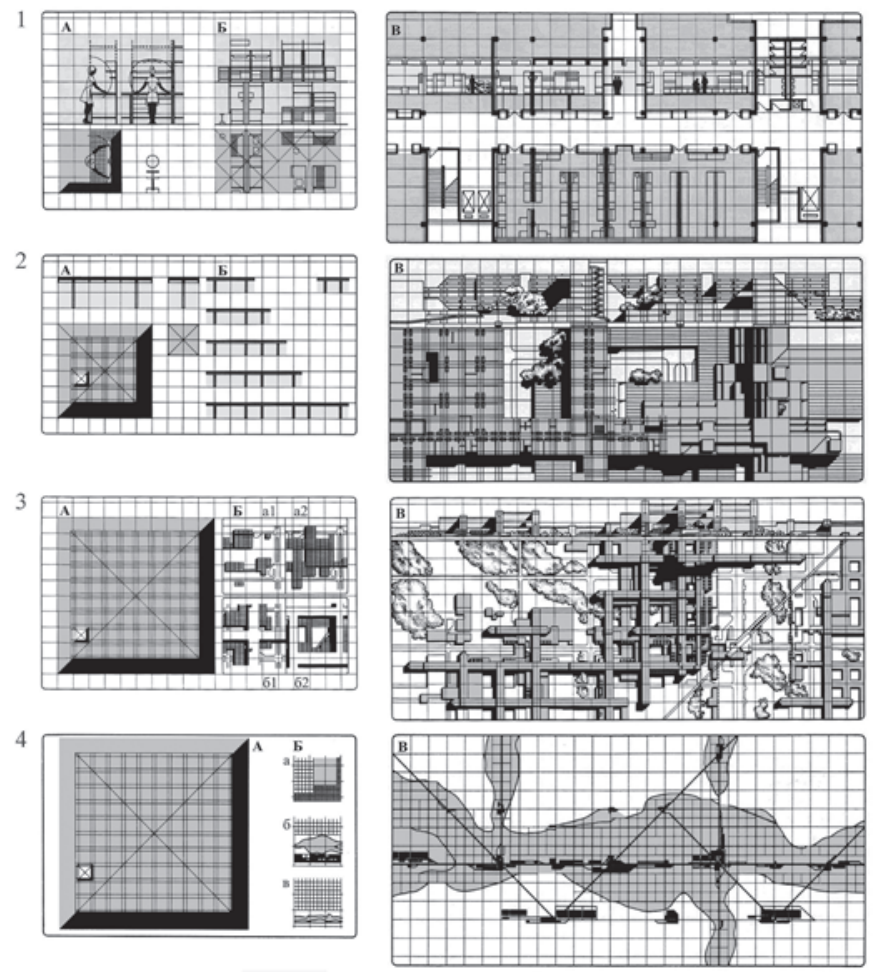

Рис. 7. Модульное регулирование при проектировании научных и инновационных объектов. 1, 2, 3, 4 - уровни пространственной организации.

1 уровень - модуль рабочего поста: $A$ - размеры и структура «рабочего поста»; Б - объединение рабочих постов и образование на их основе рабочих мест; B - типы лабораторных ячеек, их размещение в структуре объекта. 2 уровень - конструктивный модуль: $A$ - размеры и структура конструктивного модуля; типы конструктивных элементов; 5 - объединение конструктивных элементов в различные функциональные блоки; В - фрагменты пространственной структуры объекта. 3 уровень-планировочный модуль: $A$ - размеры и структура планировочного модуля; Б - варианты заполнения планировочного модуля: а1 - малоэтажная застройка павильонного типа; а2 - сплошная малоэтажная застройка; 61, б2 - смешанная застройка; В - фрагмент планировочной зоны; 4 уровень - градостроительный модуль: A - размеры и структура градостроительного модуля; $\overline{-}$ - варианты заполнения градостроительного модуля: $a$, б, в - сочетания различных функциональных зон; В - схема планировки крупного объекта на базе многоуровневой планировочной матрицы проектных решений $[7 ; 8]$. Под «регулированием» понималось предопределение основных путей развития в пространстве и времени, создание условий для поливариантности решений (рис. 8). Модульное регулирование способствовало последовательному целенаправленному архитектурному формированию научно-инновационных комплексов, подчиняя себе спонтанный процесс их развития, не стесняя свободы выбора конкретных объёмно-планировочных, художественных и стилистических решений.

Метод позволял совершенствовать пространственные решения объектов, в том числе:

- унифицировать размерный ряд всего объекта, от приборного парка до соотношений пространств лабораторного эксперимента, от коммуникаций и технологического оборудования до зон труда и отдыха;

- конфигурировать модульную решётку в соответствии с естественными условиями местности;

- обеспечивать многофункциональное использование пространства и создание гибких решений, допускающих

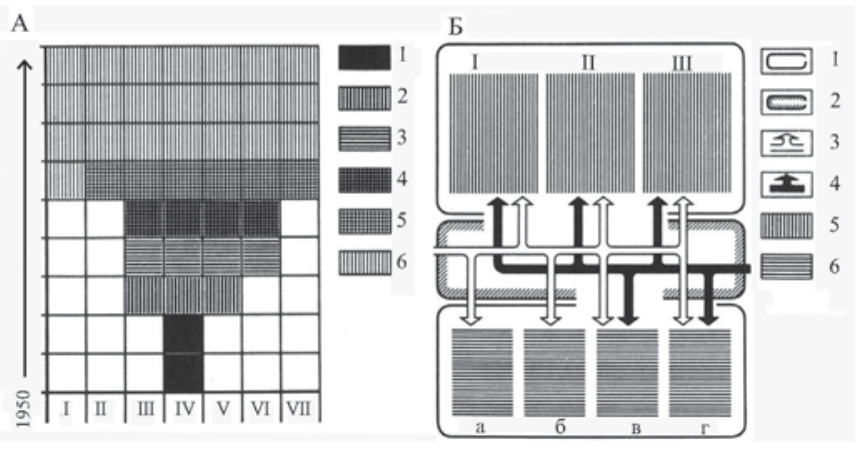

Рис. 8. Принципиальные основы методики регулирования пространственной организации научного комплекса.

А. Этапы развития унификации пространства для научных исследований. Уровни и элементы пространства: I -лабораторное оборудование; II - рабочий пост; III - рабочее место; IV - рабочая ячейка; V-здание; VI - комплекс зданий; VII - научный центр. Формы унификации: 1 - типизация лабораторных ячеек; 2 - типизация лабораторных зданий; 3 - типизация лабораторных зданий на основе сетки 6×6 м; 4 -унификация секций лабораторных зданий; 5 -унификация лабораторных комплексов; 6 - модульная организация территории научных комплексов.

Б. Схема процесса научного производства: 1 - зона деятельности; 2 - зона коммуникаций; 3 - общие коммуникации; 4 - инженерно-технологические коммуникации; 5 - научное производство; 6 - обслуживание научного производства; I, II, III - исследовательские подразделения; а - административное управление, б - обслуживание сотрудников, в - инженерно-техническое обеспечение, г - материальнотехническое снабжение 
многократное изменение и появление новых функций внутри объекта;

- соответствовать требованиям индустриальности строительных решений.

Система модульного регулирования в различной степени применялась при проектировании и строительстве объектов научного назначения на территории нашей страны.

Так, в области проектирования и изготовления установочного научного оборудования её применение имело революционный характер и сопровождалось некоторыми драматическими моментами. Если в течение многих лет лабораторное оборудование своими параметрами было привязано к технологии конкретного эксперимента, то переход к базовому модулю, основанному на эргонометрических данных, внедрение понятия «рабочий пост», основанного на человеческих габаритах, первоначально вызвал определённое сопротивление. Несмотря на это, новый модуль были внедрён в производство лабораторного оборудования для физики, химии, биологии и других областей исследований (рис. 9) [10]. При этом инженерные и специальные распределительные коммуникации, которые прежде в пределах лабораторной ячейки были привязаны к строительным конструкциям, закреплялись в структуре оборудования [9]. В этой области модульная система была использована в полной мере и создала принципиальные возможности поэлементного переформирования и гибкой трансформации рабочих мест без нарушения исследовательского процесса.

Одним из первых опытов создания гибкой планировки и серьёзным шагом на пути к общему модульному регулированию пространственной организации крупного городского научного комплекса было проектирование и строительство Института космических исследований (ИКИ) (рис. 10) [8; 12]. Унифицированные секции здесь были специально разработаны для данного комплекса. Расположенный на Профсоюзной улице вблизи ряда других научно-исследовательских учреждений, комплекс ИКИ стал доминантой в системе окружающей застройки. Здесь были обеспечены большая степень гибкости, свободной трансформации помещений и возможность замены оборудования в процессе эксплуатации. Чтобы объединить большое количество различных по назначению объёмов в целостный ансамбль, была предложена единая модульная сетка для всех сооружений. Установленный модуль определял схему внутренних дорог и инженерных коммуникаций всех сооружений. В этом проекте также решались вопросы резервирования значительных территорий для перспективного расширения института.

Важной вехой в совершенствовании метода стал реализованный проект Научного центра Сибирского отделения Всесоюзной сельскохозяйственной академии имени В. И. Ленина (ВАСХНИЛ) под Новосибирском, где система модульного регулирования реализована на практике в полном объёме (рис. 11) [11; 12]. Этот центр создавался как основная база сельскохозяйственной науки на территории Сибири и Дальнего Востока. Здесь система модульного регулирования явилась ключом, который позволил решить не только архитектурные и градостроительные проблемы, но и, что особенно важно в условиях Сибири, проблемы полносборного индустриального строительства. На основе предыдущего опыта для разработки проекта ВАСХНИЛ был выбран ряд модульных величин, положенных в основу объёмного и планировочного модулей. Эта система оп-


Pис. 9. Модульное установочное лабораторное оборудование с коммуникациями: $A$ - вытяжной шкаф; 5 - панель коммуникационная; $B$ - стол лабораторный островной; Г - стол лабораторный химический пристенный

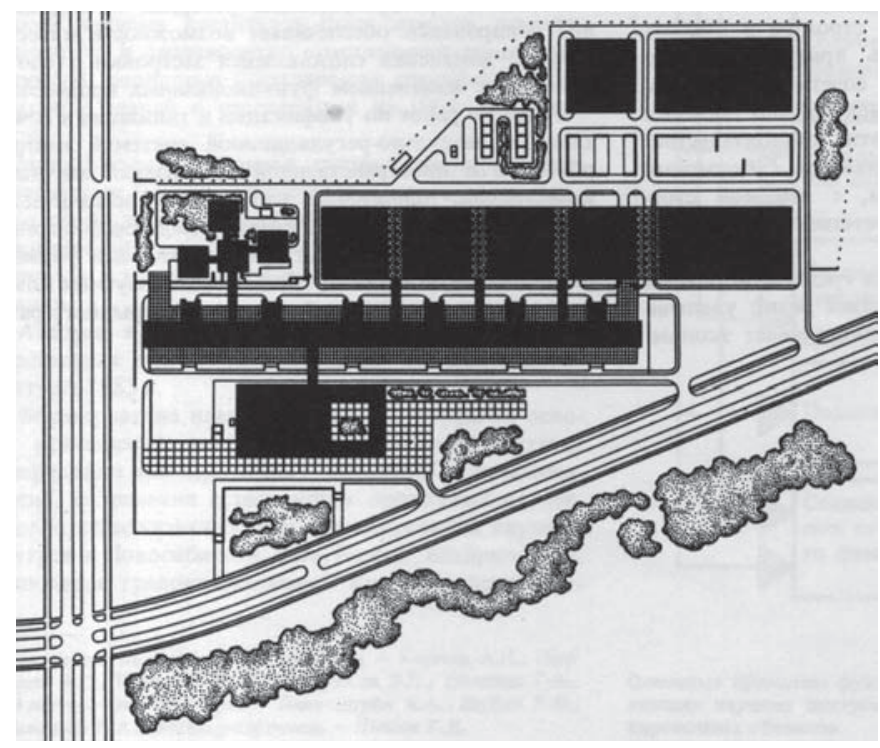

Рис. 10. Комплекс Института космических исследований. Генеральный план. Проект 
тимально соответствовала требуемым конструктивным и функциональным параметрам зданий с основным шагом 3,6 м и членению городской территории: 360 м - доступность остановок транспорта и объектов повседневного пользования, 720 м - жилые улицы, 1080 м - магистральные проезды и инженерные коммуникации. На основе объёмного модуля для строительства зданий институтов была создана, освоена и внедрена в производство комплексная серия конструкций, учитывающая специфику лабораторных зданий и рассчитанная на 100-процентную сборность.

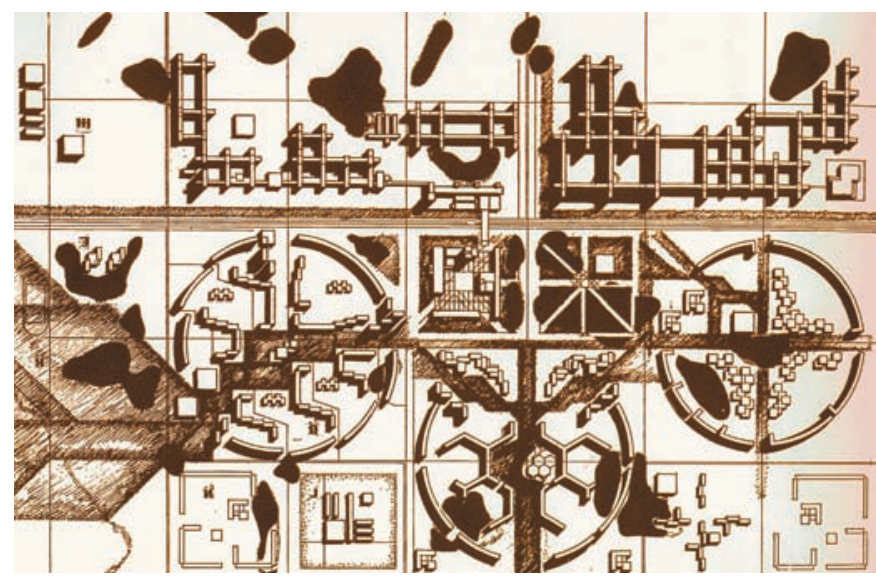

Рис. 11. Научный центр Сибирского отделения Всесоюзной сельскохозяйственной академии имени В.И. Ленина (ВАСХНИЛ) под Новосибирском. Генеральный план. Проект
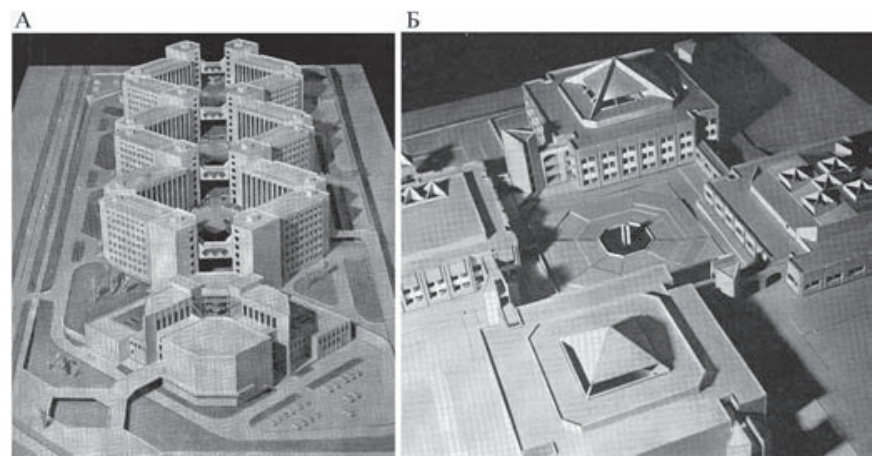

Pис. 12. А - Институт биоорганической химии. Москва. Фото с макета; 5 - Институт программных систем. Город Переславль-Залесский Московской области. Фото с макета

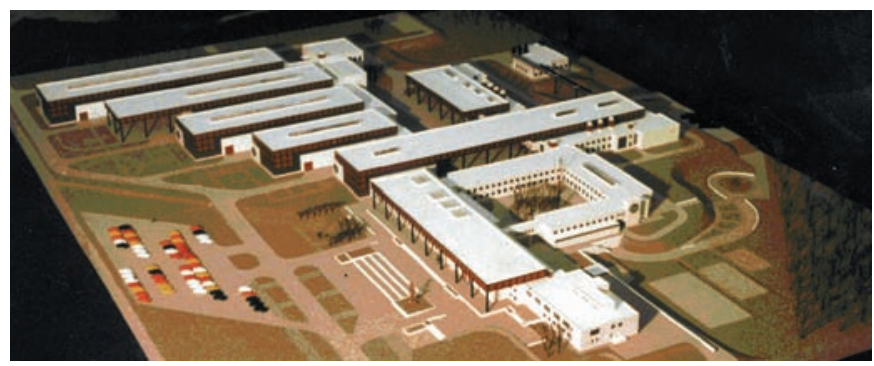

Рис. 13. Комплекс Научно-исследовательского центра технологических лазеров. Город Шатура Московской области. Фото с макета
Система модульного регулирования позволяла достичь высокой степени гибкости всей пространственной структуры градостроительного комплекса, сохраняя свободу творческих поисков. Это наглядно подтверждается реализованными проектами Института [12]. Вот некоторые из них: Институт биоорганической химии им. М. Шемякина и Ю. Овчинникова (ИБХ) в Москве на улице Волгина, Институт программных систем АН СССР в Переславле-Залесском (рис. 12), Научноисследовательский центр технологических лазеров АН СССР в подмосковной Шатуре (рис. 13) и другие. Среди проектных

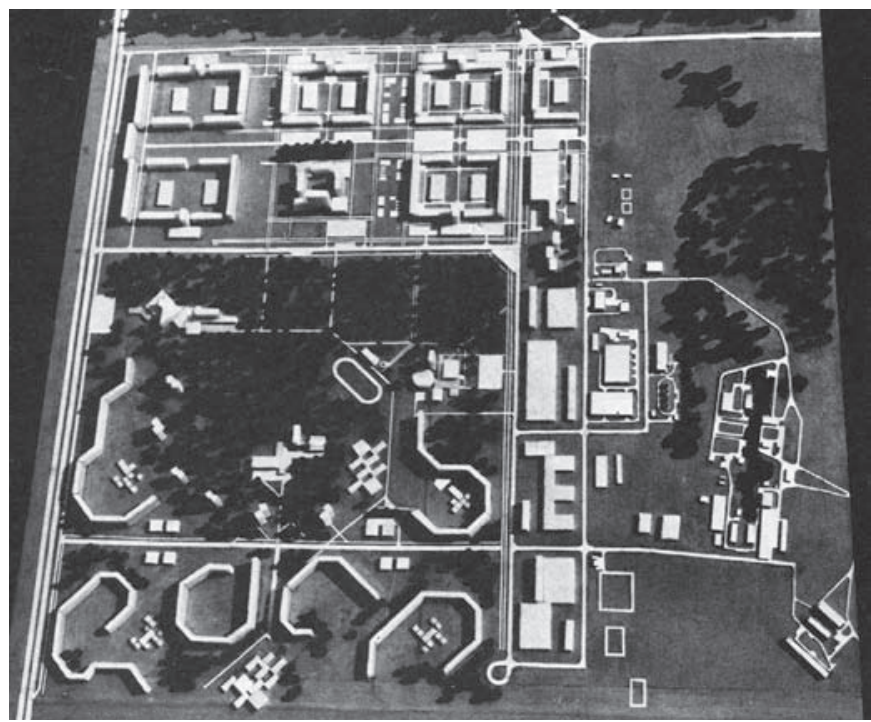

Рис. 14. Проект застройки Уральского научного центра АН ССС. Фото с макета

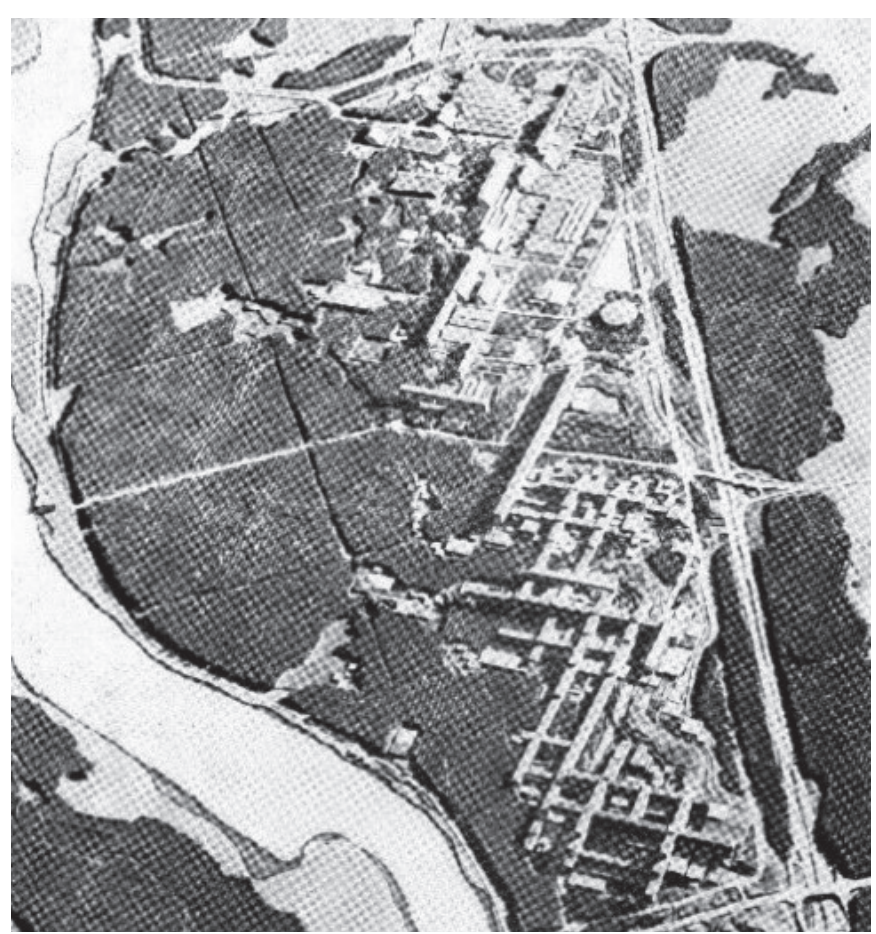

Рис. 15. Научный центр Латвийской академии наук. Фото с макета 
(в том числе конкурсных) разработок, выполненных на модульной основе, такие как: Уральский научный центр АН СССР (рис. 14), научный центр Латвийской академии наук (рис. 15), комплекс Болгарской Академии наук и Софийского университета, новый комплекс Московского Высшего технического училища им. Баумана в Щербинке (рис. 16) и другие.

В процессе поиска решения важнейшей проблемы соотношения универсальности и специализации пространства научных комплексов методы их проектирования совершенствовались и далее. В 90-е годы в связи с новыми экономическими реалиями была разработана методика проектирования научно-инновационных объектов по так называемым «ступеням специализации» [13]. Она заключалась в проектировании и строительстве здания, а также сдаче его пользователю в различной степени функционально-пространственной завершенности (рис. 17). По мере готовности универсальность пространства здания снижается, его специализация в области конкретной функции возрастает. Пользователь имеет выбор между ранними, наиболее универсальными ступенями готовности объекта, и более поздними, специализированными применительно к его требованиям. Международный опыт показывал, что наиболее востребованными для исследовательской и научно-инновационной деятельности являются пространства 3-ей - 4-ой ступеней специализации, а для виртуальных исследований и офисной деятельности - 4-ой - 5-ой ступеней (рис. 18). Методика направлена на снижение затрат на проектирование и строительство, расширение круга возможных пользователей, ускорение процесса приспособления планировочных, инженерных, технологических решений к пожеланиям конкретного пользователя. Она позволяла сократить сроки предоставления объектов пользователю, предоставить ему более широкий выбор оборудованных площадей, уменьшить издержки по ремонту и переоборудованию помещений. Тем самым достигалось разумное соотношение «цена-качество» и должные научный, инновационный и коммерческий эффекты.

Можно констатировать, что сегодняшние особенности проектирования объектов для научно-инновационного процесса имеют глубокие корни в прошлом. Так, процесс разделения научно-инновационной деятельности на так называемые общелабораторные (в том числе виртуальные) и специализированные исследования, требующие крупного, дорогостоящего, уникального оборудования, начался уже давно. Последние в силу своей сложности и высокой затратности часто даже становятся межнациональными проектами; проектирование объектов такого рода методически носит сугубо индивидуальный характер. Что до объектов общелабораторного назначения, то здесь превалируют процессы нивелирования различий между профилями и видами исследований, усреднение пространственных и технических характеристик. Таким образом, это - не исключительная особенность только сегодняшнего дня. Сходные тенденции, заключавшиеся в усреднении характеристик общенаучного

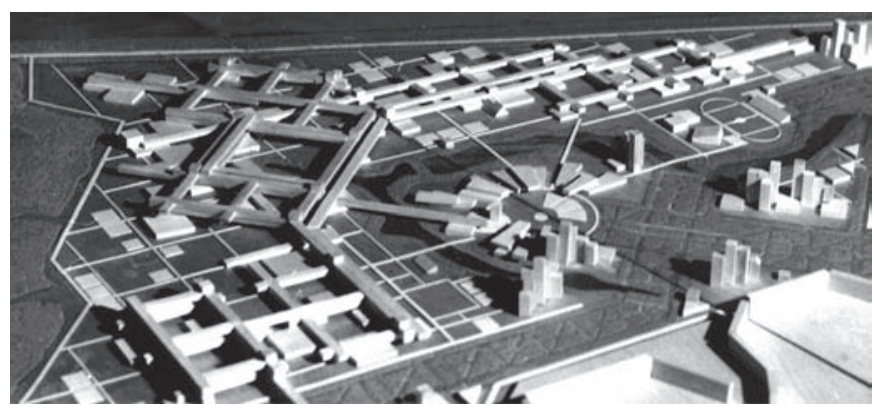

Рис. 16. Комплекс МВту им. Баумана в городе Щербинке под Москвой (конкурсный проект). Научная зона. Фото с макета

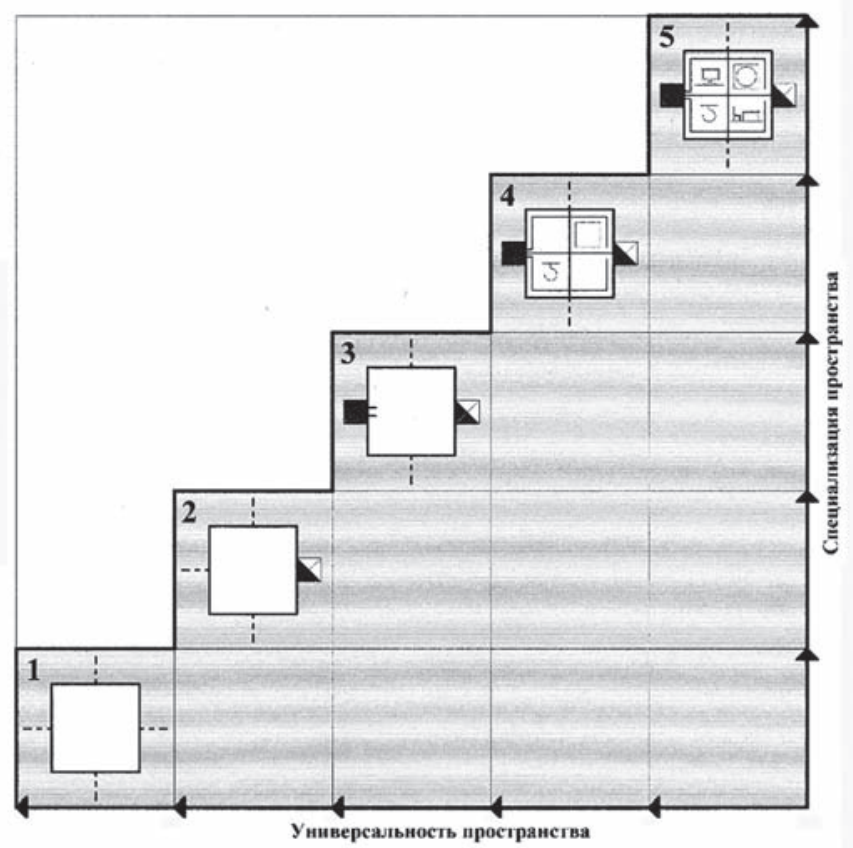

Рис. 17. Ступени специализации в процессе проектирования и строительства научно-инновационных объектов

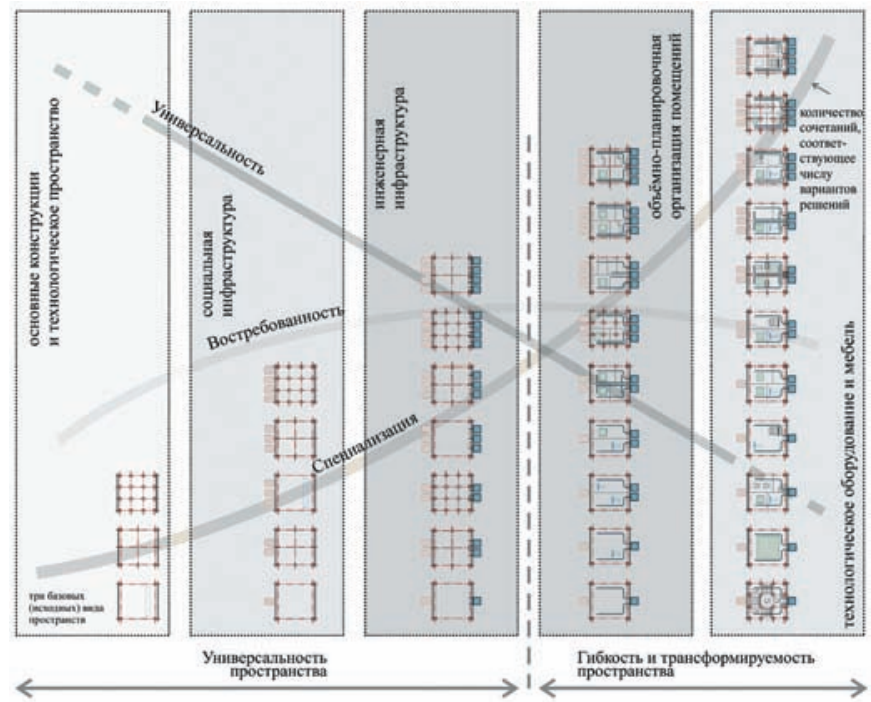

Puс. 18. Принципиальная схема соотношения универсальности и специализации пространства научно-инновационного объекта и степени его распространённости (востребованности) в проектной практике (на базе изучения международного опыта) 
процесса, наблюдались давно и ставили перед архитекторами задачи универсализации, унификации, типизации решений. В данной статье были рассмотрены преимущественно лабораторные здания, ставшие распространённым видом строительства. Для них разработанные методики позволяли получить существенный эффект. В меньшей степени методики использовались при проектировании и строительстве специальных сооружений [14].

Приведённые материалы свидетельствуют о том, что применяемые методы проектирования позволили решить сложнейшие задачи создания разнообразных научных объектов. Работы в этой области соответствовали мировому уровню требований и стандартов. Многие из построенных объектов успешно функционируют по сей день и представляют примеры достижений отечественной архитектуры. Можно утверждать, что с использованием приведённых методов в стране была создана практически заново мощная материально-пространственная база фундаментальной науки и инноваций.

\section{Лuтература}

1. Вернадский, В.И. 0 науке. Т. 1. Научное знание. Научное творчество. Научная мысль / В.И. Вернадский. - Дубна, 1937.

2. Эйнштейн, А. Физика и реальность / А. Эйнштейн. - М., 1965.

3. Бернал, Дж.Д. Двадцать пять лет спустя. Наука о науке : сборник статей / Дж.Д. Бернал. - М. : Прогресс, 1966. - С. 254-280.

4. Дианова-Клокова, И.В. Академическая наука в России в XVIII-XX веках и эволюция пространства для исследований / И.В. Дианова-Клокова, Д.А. Метаньев // Academia. Архитектура и строительство. - 2017. - № 3. - С. 35-46.

5. Метаньев, Д.А. Архитектурно-планировочные решения городка науки в Новосибирске / Д.А Метаньев, Ю.П. Платонов // Сборник материалов по обмену опытом / АН СССР, Центракадемстрой. - М. : ВИНИТИ. 1958. - С. 50-54.

6. Метаньев, Д.А. Кардинальная задача современной архитектуры и её возможное решение / Д.А. Метаньев, А.И. Томский, С.И. Хмелевский // Проблемы пространственной организации научных учреждений. НИЦ, НИИ, НИЛ. - М. : Наука, 1974. - С. 7-25.

7. Метаньев, Д.А. Модульная координация элементов и регулирование застройки / Метаньев Д.А., Платонов Ю.П., Томский А.И. // Научный центр. Модели развития. НИЦ, НИИ, НИЛ. - М., 1977. - С. 30-42.

8. Архитектура научных комплексов // Архитектура СССР. - 1976. - № 2. - С. 18-51.

9. Принципы проектирования лабораторной мебели / Д.А. Метаньев, В.Н. Шихеев, П.Г. Демчев, М.Ф. Суслин // Проблемы пространственной организации научных учреждений. НИЦ, нИИ, НИЛ. - М., 1974. - С. 101-114.

10. Установочное лабораторное оборудование. Лабораторная мебель // НИЦ, НИИ, НИЛ. - М. : Наука, 1981.

11. Проектирование научных комплексов Сибири // НИЦ, нИИ, нИЛ. - М. : Наука, 1989.
12. Архитектурные решения объектов АН СССР // НИЦ, нИИ, НИЛ. - М. : Наука, 1989.

13. Дианова-Клокова, И.В. Пространство инноваций между наукой и производством. Взгляд архитектора / И.В. Дианова-Клокова, Д.А. Метаньев // Academia. Архитектура и строительство. - 2013. - №4. - С. 5-25.

14. Проектирование зданий научного назначения / Б.А. Савельев, Ю.П. Платонов, Д.А. Метаньев, Н.Р. Фрезинская // Вестник Академии наук СССР. - 1975. - № 9. - С. 88-102.

\section{References}

1. Vernadskii V.I. 0 nauke. T. 1. Nauchnoe znanie. Nauchnoe tvorchestvo. Nauchnaya mysl' [About Science. Vol. 1. Scientific knowledge. Scientific creativity. Scientific Thought]. Dubna, 1937.

2. Einshtein A. Fizika i real'nost' [Physics and Reality]. Moscow, 1965.

3. Bernal Dzh. D. Dvadtsat' pyat'let spustya. Nauka o nauke [Twenty-five yearslater. Science of science] : sbornik statei. Moscow, Progress Publ.,1966, pp. 254-280.

4. Dianova-Klokova I.V., Metan'ev D.A. Akademicheskaya nauka v Rossii v XVIII-XX vekakh i evolyutsiya prostranstva dlya issledovanii [Academic Science in Russia in the XVIII-XX Centuries and the Evolution of Space for Research]. Academia. Arkhitektura i stroitel'stvo [Academia. Architecture and Construction], 2017, no. 3, pp. 35-46.

5. Metan'ev D.A, Platonov Yu.P. Arkhitekturno-planirovochnye resheniya gorodka nauki $\vee$ Novosibirske [Architectural and Planning Decisions of the Science Town in Novosibirsk]. Sbornik materialov po obmenu opytom [Collection of Materials on the Exchange of Experience]. Moscow. VINITI Publ., 1958, pp. 50-54.

6. Metan'ev D.A., Tomskii A.I., Khmelevskii S.I. Kardinal'naya zadacha sovremennoi arkhitektury i ee vozmozhnoe reshenie [The Cardinal task of modern architecture and Its Possible Solution]. Problemy prostranstvennoi organizatsii nauchnykh uchrezhdenii. NITs, NII, NIL [Problems of the Spatial Organization of Scientific Institutions. NITs, NII, NIL]. Moscow, Nauka Publ., 1974, pp. 7-25.

7. Metan'ev D.A., Platonov Yu.P., Tomskii A.I. Modul'naya koordinatsiya elementov i regulirovanie zastroiki [Modular coordination of elements and regulation of development]. Nauchnyi tsentr. Modeli razvitiya NITS, NII, NIL. [Scientific Center. Development Models]. NITs, NII, NIL. Moscow, 1977, pp. 30-42.

8. Arkhitektura nauchnykh kompleksov [The Architecture of Scientific Complexes]. Arkhitektura SSSR [Architecture of the USSR], 1976, no. 2, pp. 18-51.

9. Metan'ev D.A., Shikheev V.N., Demchev P.G., Suslin M.F. Printsipy proektirovaniyalaboratornoi mebeli [The Principles of Designing Laboratory Furniture]. Problemy prostranstvennoi organizatsii nauchnykh uchrezhdenii. NITs, NII, NIL [Problems of the Spatial Organization of Scientific Institutions. NITS, NII, NIL]. Moscow, 1974, pp. 101-114.

10. Ustanovochnoe laboratornoe oborudovanie. Laboratornaya mebel' [Installation Laboratory Equipment. 
Laboratory Furniture]. NITs, NII, NIL. Moscow, Nauka Publ., 1981.

11. Proektirovanie nauchnykh kompleksov Sibiri [Designing of Scientific Complexes of Siberia]. NITs, NII, NIL. Moscow, Nauka Publ., 1989.

12. Arkhitekturnye resheniya ob"ektov AN SSSR [Architectural Solutions of Objects of the USSR Academy of Sciences]. NITs, NII, NIL. Moscow, Nauka Publ., 1989.

13. Dianova-Klokova I.V., Metan'ev D.A. Prostranstvo innovatsii - mezhdu naukoi i proizvodstvom. Vzglyad arkhitektora [The Space of Innovation is Between Science and Production. The View of the Architect]. Academia. Arkhitektura $i$ stroitel'stvo [Academia. Architecture and Construction], 2013, no. 4, pp. 5-25.

14. Savel'ev B.A., Platonov Yu.P., Metan'ev D.A., Frezinskaya N.R. Proektirovanie zdanii nauchnogo naznacheniya [Design of Buildings for Scientific Purposes]. Vestnik Akademii nauk SSSR [Bulletin of the USSR Academy of Sciences], 1975, no. 9, 88-102.

Дианова-Клокова Инна Владимировна (Москва). Кандидат архитектуры, профессор МААМ (Отделение в Москве). Ведущий научный сотрудник Отделения научно-исследовательских работ ГИПРОНИИ РАН (117971, Москва, ул. Губкина, д. 3. ОНИР ГИПРОНИИ РАН). Эл. почта: indianova@mail.ru.

Метаньев Дмитрий Анатольевич (Москва). Кандидат архитектуры, действительный член МААМ (Отделение в Москве). Ведущий научный сотрудник Отделения научно-исследовательских работ ГИПРОНИИ РАН (117971, Москва, ул. Губкина, д. 3. ОНИР ГИПРОНИИ РАН).

Dianova-Klokova Inna Vladimirovna (Moscow). Candidate of Architecture, Professor of the Moscow branch of the International Academy of Architecture. Leading researcher of the Department of research works of the GIPRONII RAN (117971, Moscow, Gubkina st, 3. GIPRONII RAN). E-mail: indianova@mail.ru.

Metanyev Dmitry Anatolyevich (Moscow). Candidate of Architecture, Full-Fledged Member of the Moscow branch of the International Academy of Architecture. Leading researcher of the Department of research works of the GIPRONII RAN (117971, Moscow, Gubkina st, 3. GIPRONII RAN) 